\title{
The coding of topological relations in verbs: the case of Likpe (Sekpelé)
}

FELIX K. AMEKA

\section{Abstract}

This article examines the grammar, use and meaning of fifteen verbs used in the Basic Locative Construction (BLC) of Likpe - a Ghana-TogoMountain language. The verbs fall into four semantic subclasses: (a) basic topological relations: tó 'be.at', tókó 'be.on', kpé 'be.in', and fi 'be.near'; (b) postural verbs: sí 'sit', nỹ̃ 'stand', fáka 'hang', yóma 'hang', kpósó 'lean', fusá 'squat', and labe 'lie'; (c) “distribution” verbs: kpó 'be spread, heaped,' and ti 'be covered'; and (d) 'adhesion" verbs: má 'be griped, be fixed' mánkla 'be stuck to'. Likpe locative predications reflect an ontological commitment to the overall topological relation between Figure and Ground and are not focused just on the Figure or the Ground. Various factors determine the choice of "competing" verbs for particular scenarios: animacy, nonindividuation of the Figure, permanency of the configuration and the speaker's desire to be referentially precise or to present stereotypical information. It is demonstrated that in situations where there is a choice, speakers tend to use the more general verbs (stereotype information). The implications of this tendency for the development of a language from a multiverb language using several verbs (e.g., 15) in its BLC to using only a small-set of verbs in its BLC, just as some of Likpe's neighbors have done, are considered.

\section{Introduction}

The purpose of this paper is to describe the grammar, semantics and use of a set of 15 contrasting locative verbs that function in the basic locative construction (BLC) in Likpe, a Ghana-Togo-Mountain (GTM) language spoken by about 30,000 people in Ghana (West Africa). The GTM languages, although classified as Kwa (Stewart 1989; Williamson and Blench 2000), are a group of 14 languages which have "some vocabulary 
resemblance to the KWA languages, but the Class system is reminiscent of BANTU" (Westermann and Bryan 1952: 96, caps in original). Even though Likpe and the other GTM languages, such as Avatime (see, e.g., Schuh 1995), have an active noun class system like the Bantu languages, they do not show reflexes of the locative noun classes of the Bantu type (see, e.g., Neumann 1999). Instead, the languages seem to have a set of locative verbs that encode some of the features expressed in the locative classes, e.g., verbs meaning 'be.on' or 'be.near' and 'be.in' that are used in expressing the basic locative function, as we shall see below (see also Ameka 1999; Dakubu and Ford 1988).

Languages can be typologized on the basis of the number and type of verbs they use in basic locative predications (Ameka and Levinson this issue). According to such a typology, Likpe is a multiverb language since it uses a set of 15 contrasting verbs in its BLC. The BLC is a nonelliptical clause that represents the answer to a "where-search" question. Likpe is like Tzeltal, another multiverb language whose system is better known, in having only one general locative preposition, namely, the variants lí lá 'LOC'. Likpe and Tzeltal are also alike in having a form class of elements that designate the axial parts and spatial regions of the Ground nominal. The form class in Tzeltal is that of spatial nominals which tend to be used to augment the Ground information contained in the verb. The form class in Likpe is a postpositional class; the postpositions have grammaticalized from spatial nominals, most probably, as a consequence of contact-induced grammatical change and areal grammaticalization (Ameka 2007). The neighboring languages Akan and Ewe (the dominant lingua franca) all have postpositions and prepositions (see e.g., Ameka 2003; Ameka and Essegbey 2006; Heine et al. 1991).

While Likpe and Tzeltal are both multiverb languages and have these similarities, there are differences between them in the commitments they make in the coding of spatial information in the verbal component of locative utterances. As Bohnemeyer and Brown (this issue) point out Tzeltal speakers show a strong preference in their locative utterances for specifying how the Figure is spatially dispositioned and that the bulk of the semantics of the verbs is Figure-related (see also Brown 1994; Levinson 2003). Likpe speakers, on the other hand, use verbs which are committed to the overall configurational geometry of FigureGround relation. The focus of their meaning is not on the properties of the Figure or of the Ground but on the 'topological relation' between them. As an illustration, consider the kinds of discriminations Tzeltal makes in talking about contact between an inanimate Figure and a horizontal flat surface such as a table top coded in the following verbs (cf. Brown 1994): 

(1) pachal ta mexa 'be.loc (of hemisphere upright)' mujul ta mexa 'be.loc (of inverted hemisphere)' waxal ta mexa 'be.loc (cylinder)' lechel ta mexa 'be.loc (wide, flat e.g., frying pan)' chepel ta mexa 'be.loc (of bulging bag, supported beneath)' pakal ta mexa 'be.loc (of blob with downwards surface)' cholol ta mexa 'be.loc (of objects in a row)'

For all the scenarios represented in (1), Likpe, by contrast, uses only one verb tókś 'be.on.surface' irrespective of the features of the Figure. Tzeltal makes fine distinctions with respect to a Ground object as well, similar to those for the Figure, e.g., that it is a container vs. a supporting surface. In this area too, the Likpe verb for describing such scenarios, as we shall see below, says nothing about the Ground but rather focuses on the configurational relation between the Figure and the Ground.

The Likpe data are thus of interest for our understanding of multiverb languages that do not have as many verbs as Tzeltal. (Tzeltal has about 100 members in the positional form class.) One of the differences hypothesized between the small-set (postural) languages (for example, Dutch, see e.g. van Staden et al. [2006] or Goemai, see Hellwig [this issue]) and the multiverb languages is that the verbs in the former classify nominal concepts and are used presuppositionally while the verbs in the latter classify referents and are used assertionally. Thus languages of the two types differ in how they characterize locative relations involving multiple Figures in different orientations, e.g., a locative scenario with 4 bottles lying on their side and 3 others standing on their bases (PSPV 46). In a postural type language like Yélî Dnye (Rossel Island) it is not false to reply to the where question in respect of such scenes that the 'the bottles are standing on the table' (see Levinson 1999, 2003). This is because in this language bottles 'stand' by default. In Likpe, however, the preferred response is to specify the exact configuration of the bottles, including their actual orientation, as in (2a). Furthermore, it is equally felicitous and truthful to respond with the 'be.on.surface' verb táká to localize the bottles without paying attention to the orientation of the individual bottles as in (2b).

a. o-tsywá nyə a-na labe lá o-punu
AGR-three stand AGR-four lie LOC CM-table
əsúá
surface

b. bo-tóká ló o-punu əsúá

3PL-be.on LOC CM-table surface

'They are on the upper surface of the table' 
Although the utterance in (2b), at first glance, looks like the presuppositional use of a default classifying verb in a postural type language like Yélî Dnye, it is only superficially so. In fact, it is an assertional use of the locative verb that affirms the current and exact location of the bottles. It does not convey any information about the Figure's orientation as (2a) does. The utterance in (2a) is used in order to give detailed specification about the individual members of the multiple Figures. A motivation for this may be to signal contrast between the orientations of the individual items. In fact it is only in such contrastive contexts that the posture verb labe 'lie' may be used to localize inanimate objects.

In the next section, I provide a brief typological overview of the language. The Likpe Basic Locative Construction (BLC), the "wheresearch" question and the form class of locative verbs that occur in them are presented in Section 3. Alternative constructions in which the verbs occur are also characterized. In Section 4, the uses and meanings of the individual verbs are described paying attention to their extensions. Section 5 summarizes the discussion and situates the Likpe data with respect to the localizability hierarchy. The database for the study includes spontaneous spoken texts collected in the field by the author as well as responses to various stimuli designed for the investigation of topological relations and the semantics of positional verbs by members of the Language and Cognition Group at the Max Planck Institute for Psycholinguistics, Nijmegen: Topological Relations Picture Series (TRPS), Picture Series for Positional Verbs (PSPV) and also the Topological Relations: Containment Picture Series (CONT) and the Topological Relations: Support Picture Series (SUP). ${ }^{1}$

\section{Likpe: a typological profile}

Likpe is a tone language with three level tones High, Mid and Low as well as Falling and Rising which are phonetically generated. Each syllable is a tone bearing unit. It has an eight vowel system with both oral and nasalized counterparts. It has a root-controlled Advanced Tongue Root (ATR) vowel harmony system where the first syllable of the stem determines the ATR value of the prefixes. For instance, the two syllables in the noun stem -kpelé 'Likpe' have opposite ATR values, but it is the ATR value of the first syllable that determines the ATR value of prefixes:

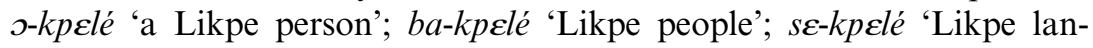
guage'. The value of the vowels in the verb root also determines the value of the verbal prefixes but not of the verbal suffixes. 
Likpe is an SVO language. Grammatical relations are determined by constituent order supported by cross-referencing of the subject on the verb and the forms of pronominal arguments in the clause. Objects are not cross-referenced on the verb. The subject cross-reference markers are neutralized with respect to number of the participants and they are distinct from the subject pronominal clitics and other pronominal forms. One can distinguish between two sets of subject cross-reference markers, which, for want of better terms, will be referred to as: the nondependent and the dependent or relative sets. Roughly speaking, the former set is used in pragmatically unmarked main clauses while the latter, as the suggested label indicates, is used in dependent as well as pragmatically marked clause types such as relative clauses, term focus and content question constructions. The nondependent cross-reference is unmarked in stative constructions (see example [2a]) and is realized as a Vowel whose form depends on the ATR and height value of the vowel of the verb root (see [3a] and [3b]). Pronominal subjects in nondependent contexts are not cross-referenced on the verb.
a. Pius
o-bá
$m f o$
NAME SCR-come here
'Pius came here'
b. be-sió
bá-mó
á-no
li-kpéfí
CMPL-woman
AGR-DET SCR-hear
CM-child
ná-mó

eto
$k e-w i$
AGR-DET POSS CM-cry
'The women heard the child's cry'

The dependent or relative cross-reference markers are $n$ - and $l V$ - where the $\mathrm{V}$ harmonizes with the vowel in the verb stem. The choice of $n$ - or $l V$ - seems to depend on temporality: the former is used with general present time hence it gets used in present stative constructions (see Section 2). The latter tends to be associated with past or nonpresent situations and hence more active situations. The focus counterpart of (3a) with a dependent cross reference marker on the verb is (4a).
a. Pius
li-bó
$m f o$
NAME SCR-come here
'PIUS came here'
b. Sáka
aa-té
be-sió.bí bá-mó
Sekpelé
NAME SCR:HAB-teach CMPL-girl AGR-DET Likpe
'Saka teaches the girls the Likpe language'

In a double object construction including causative three place constructions, the GOAL argument precedes the THEME (see $4 \mathrm{~b}$ ). The causative 
counterpart of some of the locative verbs, as we shall see below, involves instances of the double object construction. In predicative possessive structures, the possessor and the possessed can be linked to either the subject or object function. That is to say the linking may involve FigureGround reversal (see Kita 2007).

Likpe has three verb derivational morphemes or suffixes: -kó 'ASSOC', -fá 'TELIC' and -sá 'CAUS'. Some of the locative verbs are lexicalized causative forms: kpəsá 'lean' and fusá 'squat, be.upside.down'. Other verbs such as fáka 'hang, point suspension' can be productively causativized with the causative morpheme. Likpe also makes use of serial verb constructions (SVCs) in which the verbs must share the same subject. The subject is expressed on subsequent verbs by a subject pronominal concord marker. In example (5) the two verbs in the SVC are locative verbs and since the clause is a static locative construction, the first verb $s i$ 'sit' does not take an overt cross reference marker. The second verb $f i$ 'be.near' is, however, marked by a pronominal form that agrees with the subject, 'the dog'.

$\begin{array}{llllll}o-k p \hat{a} & \text { á-má } & \text { sí } & \text { o-fi } & \text { wá } & \text { dí-yó } \\ \text { CM-dog } & \text { AGR-DET } & \text { sit } & \text { 3SG-be near } & \text { 3SG } & \text { CM-room }\end{array}$

'The dog is sitting near its house'

(TRPS 6)

Negation is marked on the verb by a nasal prefix which occurs immediately before the verb root and after any other verbal markers like tense markers or subject proclitics. Most of the locative verbs employ this morphological device. There is however a negative locative existential suppletive counterpart for the verb kpé 'be.in', namely, -m-bá 'not happen'. The sentences in (6a) and (6b) illustrate its use for negative location and negative existence respectively.
a. u-m-bó
lá dí-yó
3SG-NEG-EXIST LOC CM-house
' $\mathrm{S} /$ he is not at home'
b. Onanto ó-m-bó
God SCR-NEG-EXIST
'God does not exist'

Modifiers follow the head in a noun phrase and, except for the qualifiers, agree with the noun head in number and class. The possessor precedes the possessed in a possessive nominal phrase. Pronominal possessors are juxtaposed to the possessed while nominal possessors are linked by a possessive marker (e) to 'POSS'. 


\section{The basic locative construction and other related constructions}

\subsection{The basic locative construction}

The basic locative construction (BLC) in Likpe is made up of a NP which is the Figure and the subject of the clause followed by a verb selected from the form class of contrasting locative verbs and an obligatory locative adjunct phrase. The locative adjunct phrase is a prepositional phrase headed by the only general locative preposition in the language-li/ló 'LOC'. ${ }^{2}$ The complement of the prepositional phrase is a postpositional phrase headed by a postposition which specifies the search domain or the active zone of the reference object relevant for the localization of the Figure. In the Likpe BLC, the expressions representing the Figure, the verb and the reference object cannot be omitted. The postpositions which designate the search domain and the general locative preposition are omissible under certain conditions.

The locative preposition is normally not omissible except when the Ground where the Figure is localized is inherently locative such as ka-só 'land, ground, earth' and/or relates to the stereotypically expected location of the Figure such as di-yó 'house, room' or ka-tó 'sky, heaven'. Thus the response to the question "Where is God?" is just given as o-kpé $k a$-tó 'He is in heaven' without the locative preposition. Similarly, one commonly hears an answer like o-kpe di-yó ' $\mathrm{S} / \mathrm{he}$ is in the house/room' without the locative preposition, to questions about the whereabouts of people. The postposition can, however, be elided under certain conditions e.g., when the information it carries is redundant because it is encoded in the verb. The postposition in example (7) below, for instance, can be left out since 'the surface' it signifies is lexicalized in the verb. The postposition can also be left out when the specific search domain information is recoverable from the reference object as in the example in Note 2, or in the case of locating things on a part of the body, as we shall see below. Example (7) is a fully labeled instantiation of the BLC in Likpe, which is an answer to the question 'where is the cup?' stimulated by TRPS 1 'cup on table'.

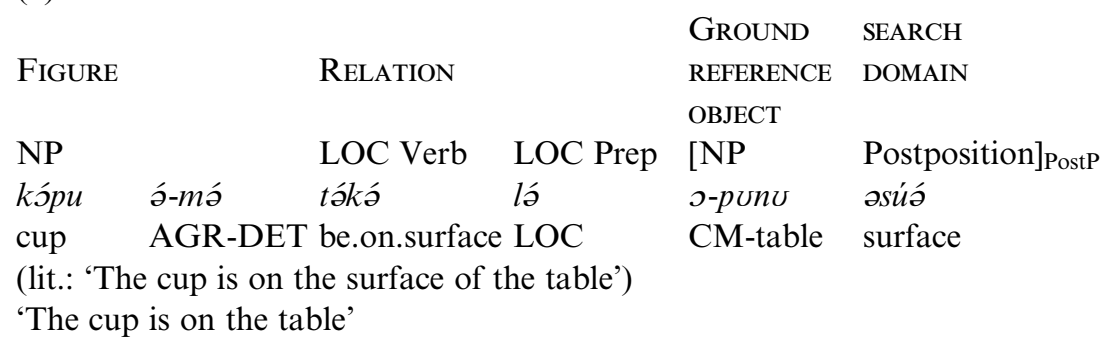


Table 1. Likpe postpositions

\begin{tabular}{|c|c|c|}
\hline Juxtaposed & Juxtaposed/possessive linker & Possessive linker \\
\hline əsúá 'surface' < BODY & $\begin{array}{l}\text { ka-tó 'up, above' < SKY, } \\
\text { HEAVEN }\end{array}$ & $\begin{array}{l}a \text { a-ks 'vicinity, place' } \\
<\text { ?LIVER }\end{array}$ \\
\hline$(\dot{e}-) f l o$ 'near, place' & li-si 'peak, summit' < HEAD & ko-tosi 'edge' \\
\hline ká-lo 'under' & $s \varepsilon^{\varepsilon}-t \overline{~ ' f r o n t '}$ & kə-siá 'entrance' \\
\hline \multirow[t]{4}{*}{ kə-mí 'inside' } & ká-ma 'back, behind' < BACK & \\
\hline & ká-fo 'inside' < STOMACH & \\
\hline & $n-t i$ 'midst' & \\
\hline & kə-nyã 'opening' < MOUTH & \\
\hline
\end{tabular}

The postpositions constitute a distinct grammatical class which, as noted earlier, is emerging in the language due to areal pressure. They are evolving from body part and environment terms (see Table 1 for some putative sources). The postpositional items are bound to other NPs and together with these NPs they form a postpositional phrase constituent. The postpositional phrases have the external distributional properties of NPs. As such they can function as arguments or adjuncts or as complements of prepositions, as in example (7).

There are two modes of linking the postpositions to their dependent NPs depending on the degree of grammatical evolution of the postposition. The items that are fully grammaticalized such as osúa 'surface' are only linked by juxtaposition. Others which are at the initial stages of being grammaticalized such as áks 'vicinity' are linked by the possessive marker eto 'POSS' (see Table 1). Some other postpositional items can be linked either by juxtaposition or by the possessive marker, indicating grammaticalization in progress. For instance, in example (8) below, the postposition can be optionally linked to the dependent NP with the possessive linker.

$$
\begin{aligned}
& \text { lé-kpe kpé li n-tu li o-lotsyi (eto) } \quad k a-f o ́ \\
& \text { CM-fish be.in LOC CM-water LOC CM-pot POSS inside } \\
& \text { 'The fish is in the water in the pot' }
\end{aligned}
$$

Moreover, even though the postpositional forms may be heterosemic and homophonous with their nominal sources, they display morphosyntactic properties that are distinct from those of the nominal forms. For example, the postpositions unlike their nominal counterparts cannot be modified and they no longer vary with respect to number marking. Thus the 
form kənỹ as a postposition has only this one form and can be glossed as 'entrance, opening'. However, as a body part term, the same form glossed as 'mouth' can be pluralized as $n$-nỹ̃ 'mouths'.

While the use or otherwise of the possessive marker to link the postposition to the dependent NP is an indication of grammaticalization in progress, sometimes the possessive linker strategy is used to make a distinction between a Figure in contact with the highest part of a reference object and one where there is no contact between the Figure and the reference object. This distinction manifests itself in the characterization of locative scenarios involving an "above" relation such as "cloud above mountain' (TRPS 36), and 'lamp above table' (TRPS 13), as in example (9).

\section{(9) o-kanía fáka lí o-púnú ó-má eto \\ CM-lamp hang LOC CM-table AGR-DET POSS \\ ka-tó}

CM-up/heaven

'The lamp is hanging above the table'

The fifteen verbs that can occur in the BLC can be subclassified into semantic groups:

I. Verbs that lexicalize the primary topological relations, in the Piagetian sense, of coincidence, tá 'be.at', contact and support, tókó 'be.on.surface', enclosure or containment, kpé 'be.in', and propinquity, $f i$ 'be.near'. The last of these is rather marginal.

II. Verbs that primarily have postural semantics: si 'sit', nyz̃ 'stand', fáka 'hang (point suspension)', yóma 'hang (partial contact with and support from reference object)', ${ }^{3}$ kpásó 'lean', fusó 'squat, be.upside.down', labe 'lie'. The last of these has limited use when the Figure is inanimate (see example [2a]).

III. A pair of verbs that relate to distribution: $k p o$ 'be spread, heaped, poured' and $t i$ ' 'be covered'.

IV. A pair of verbs that focus on adhesion or attachment: $m a$ 'be griped, be fixed' mánkla 'be stuck to'.

These verbs are semantically stative and in their primary use are intransitive and do not host subject cross-reference markers. However, they can occur in several other constructions such as a transitive construction in which they can take a subject cross-reference marker. In addition, they are marked with the $n$ - dependent marker when they occur in the "where-search" question, as we shall see in the next section. 


\subsection{The "where-search" question}

In a Likpe "where-search" question, the interrogative word sé 'where' occurs initially followed by the expression representing the Figure, whose location is being questioned, followed by the verb. Being a present stative content question, the Figure (the grammatical subject) is cross-referenced by the form $n$-. The question utterance that elicited the response in (7) is given in (10).

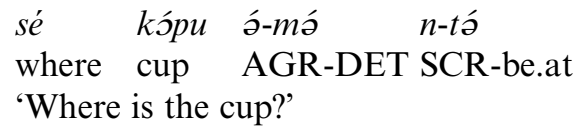

Any of the fifteen locative verbs can be used in the "where-search" question. The use of particular verbs can be understood from general presumptive meanings (cf. Levinson 2000). In fact, the verbs seem to be partially ordered with respect to general and specific configurational meanings. The prototypical topological verbs tó 'be.at', tókó 'be.on', and kpé 'be.in' with their general meanings seem to pair with the rest. For instance, in the context of elicitation by picture stimulus depicting a locative scenario, given that the configuration can be assumed (e.g., stick against a tree, PSPV1) the more specific verb kpósá 'lean' rather than the general verb tó 'be.at' is preferred. In addition, the verbs tó 'be.at' and $k p e ́$ 'be.in' can be used to ask about the location of entities when the specific configuration or relation is not assumed. However, the choice of one or the other in a particular context seems to be determined by the animacy of the Figure. Human Figures cannot be asked about or localized with tá 'be.at' and inanimate Figures cannot be asked about with kpé 'be.in' (although they could be localized with it). Thus one can ask about the location of a mango (an inanimate thing) using tó 'be.at' but if it were contained in something like a basket, one would have to localize it with kpé 'be.in', the verb that describes the containment configuration, as opposed to tó 'be.at' which only talks about being located at a place generally.

\subsection{Existential and possessive constructions}

Each of the three prototypical topological verbs tó 'be.at', tókś 'be.on', and kpé 'be.in' can occur in other stative constructions - the existential and the possessive - that are formally and semantically different from the locative. In these contexts also, there is no overt subject 
cross-reference marker on the verb. The existential construction is however different from the locative construction in not requiring a locative adjunct phrase, as the sentences in (11) illustrate.

$$
\begin{aligned}
& \text { a. ka-so kpé } \\
& \text { CM-land be.in } \\
& \text { 'There is land' } \\
& \text { [Settlement History text, EKO] } \\
& \text { b. 'u-mə tó-ə } \\
& \text { CM-town be.at-Q } \\
& \text { (lit.: 'Is there the town?') } \\
& \text { i.e., 'How is the town?' (a greeting question) }
\end{aligned}
$$

In contrast to the one-place existential construction, the possessive construction is a two-place construction with no subject cross-referencing on the verb. There are two subconstructions with different surface order realizations of the possessor and the possessum. In one, the possessor is linked to the subject and the possessum to the object, as in (12a) and (13a). In the other, there is Figure-Ground reversal where the possessor is linked to the object function and the possessum to the subject function, as in (12b) and (13b) (cf. Kita 2007).
a. kópu ó-má táká kú-tsye cup AGR-DET be.on CM-crack
'The cup has a crack'
b. kú-tsye tóká kópu ó-mó
CM-crack be.on cup AGR-DET
'There is a crack on the cup'
(13) a. Saka kpé a-taabi
NAME be.in CM-money
'Saka has money'
b. a-taabi kpé Saka
CM-money be.in NAME
'Money is possessed by Saka'

The possessive constructions in which these three verbs occur are not only used for predicating the possession of material and concrete things, they are also used for the possession of abstract qualities, as illustrated in (14), where the physical property of the load is described.

(14) di-kə diá-mó kpé ka-lenle

CM-load AGR-DET be-in CM-heaviness

'The load is heavy' 


\subsection{External possessor construction}

A variation on the Basic Locative Construction in Likpe is an external possessor construction. It is used to localize entities on parts of the body such as adornments and clothing. In this construction, the Figure is the subject, but like other stative constructions, it is not overtly cross-referenced on the verb. The possessor of the part where the Figure is located is linked to the object function and occurs immediately after the verb. This is followed by an obligatory locative adjunct headed by the general locative preposition whose complement is the body part term which represents the active zone or search domain of the localization. It is not possible to use a postposition in this construction. It is locative situations that pertain to Level $\mathrm{V}$ of the localizability hierarchy (see Ameka and Levinson, this issue) that employ the external possessor construction strategy. Thus (15) is an instantiation of the external possessor construction and is the first and preferred response to the "where-question" in relation to the scenario of 'ring on finger' (TRPS $10)$.
le-súkpe kpé wa li lá-nimí
CM-ring be.in 3SG LOC CM-finger
(lit.: 'a ring is on him/her at a finger')
'S/he has a ring on the finger'

Before turning to the nonstative constructions, the features that distinguish the various stative constructions from one another are summarized in Table 2.

Notice from the table that the locative constructions - the BLC and the external possessor construction - only differ with respect to the type of argument structure construction involved. Furthermore they both require a locative adjunct constituent, which is one defining feature of locative constructions in the language.

Table 2. Summary of the stative constructions

\begin{tabular}{lllll}
\hline Construction & $\begin{array}{l}\text { Basic locative } \\
\text { construction }\end{array}$ & $\begin{array}{l}\text { Existential } \\
\text { construction }\end{array}$ & $\begin{array}{l}\text { Predicative } \\
\text { Possession }\end{array}$ & $\begin{array}{l}\text { External } \\
\text { Possessor }\end{array}$ \\
\hline $\begin{array}{l}\text { Argument structure } \\
\text { construction }\end{array}$ & intransitive & intransitive & transitive & transitive \\
$\begin{array}{l}\text { Locative adjunct? } \\
\text { Figure-Ground reversal? }\end{array}$ & $\begin{array}{l}\text { obligatory } \\
\text { no }\end{array}$ & $\begin{array}{l}\text { optional } \\
\text { not applicable }\end{array}$ & $\begin{array}{l}\text { optional } \\
\text { possible }\end{array}$ & $\begin{array}{l}\text { obligatory } \\
\text { no }\end{array}$ \\
\hline
\end{tabular}




\subsection{Nonstative constructions}

All the verbs that occur in the BLC and the other stative constructions discussed up to this point also occur in nonstative constructions. The main distinguishing feature when the verbs occur in the nonstative constructions is that they take the nondependent subject cross-reference marking. I will discuss the monoverbal and the serial verb constructions in turn.

All the verbs can occur in transitive constructions. In one type of transitive construction, the subject argument is the Figure and the object is the Ground. We shall refer to this as the Theme-Locative construction. The structure describes the resultant state or configuration of a FigureGround relation due to some prior action. Because of the dynamic nature of such situations, the subject is cross-referenced on the verb. For instance, the verb $t i$ 'be.covered' can be used in the BLC, as in (16a), and hence there is no overt cross reference marker. In (16b), however, the verb is used in a dynamic two-place construction and the subject is now cross-referenced on the verb. The sentence in (16b) has a result-stative situation occurring due to a prior action, namely, the plaster having been put over the wound.

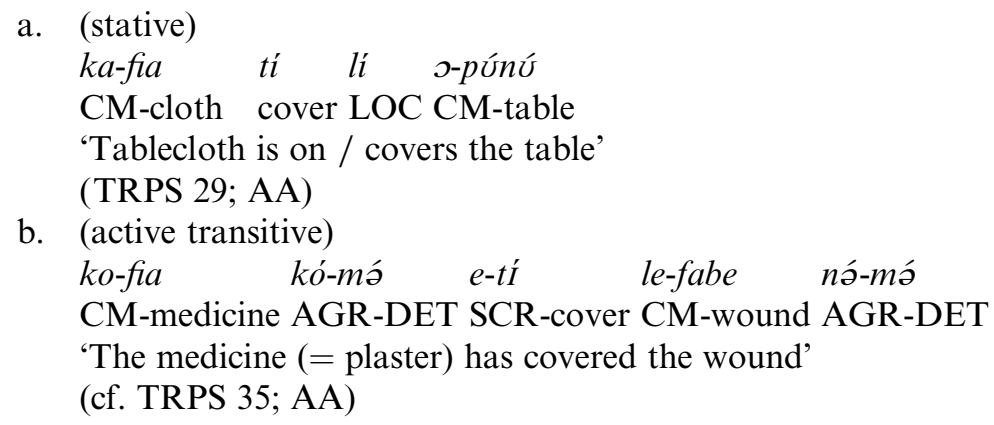

Most of the verbs can also occur in an agentive transitive and/or ditransitive construction. These structures have a caused locative reading. Thus if someone caused water to be poured or to be in a configuration in a location such as a tank, it can be described as in (17).

$$
\begin{array}{llll}
\text { Sáka } & a-k p o ́ & n-t u & \text { li tánki } \\
\text { NAME } & \text { SCR-be.poured } & \text { CM-water } & \text { LOC tank } \\
\text { 'Saka poured water into the tank' } &
\end{array}
$$

Roughly speaking, the agentive transitive construction involving the locative verbs signals that an effector did something to another entity (linked to the grammatical object function and is the Figure). The effector did it because they wanted the Figure to be in a certain configuration with the 
Ground (a location), coded as the locative adjunct in the example in (17) above.

Furthermore, the locative verbs can occur in three place constructions following the order of double object constructions where the GOAL precedes the THEME. These typically convey the idea that someone is causing a Figure entity (the second object) to be placed in a certain configuration with respect to a Ground object (the first object), the GOAL. If the subject argument is not realized as a pronominal it is cross-referenced on the verb. Thus when someone puts a knife onto the surface of a pumpkin fruit and damages it, the scenario is described with the verb tóká 'be.on.surface' in a three place construction, as in (18). In such structures also, the verbs have a causative reading.
$u$-tókə
$l \varepsilon-b o$
nó-mó
le-siabi
3SG-be.on CM-pumpkin AGR-DET CM-knife
'He put a knife to the pumpkin'

An act of placing or putting something in a configuration is typically described by a serial verb construction (SVC) involving the handling verb $f i$ 'take, use' as the first verb and one of the locative verbs as the second verb. The first object is the Figure which is put in a configuration (on a surface, in a container, leaning etc) at a place expressed in a locative constituent after the configurational verb. For instance, if someone just placed a knife on the pumpkin, the SVC in (19), instead of the double object construction in (18) is used.

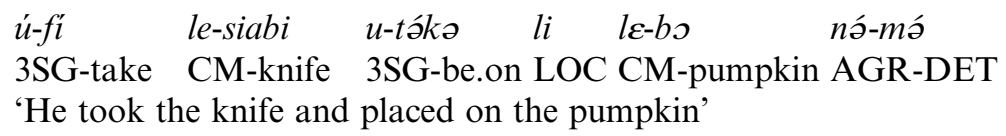

\subsection{Summary of constructions}

The locative verbs participate in various stative and nonstative constructions. The distinguishing feature of the two classes of constructions is that in the former, the subject is not overtly cross-referenced on the verb in pragmatically unmarked contexts. The verbs, however, take a subject cross-reference marker in the latter constructions. One can relate the constructions to Talmy's $(1985,2000)$ typological claims concerning lexicalization patterns of postural (and positional) verbs and their relation to aspect and causation. Talmy proposes that positional verbs fall into three "aspect-causative types": stative "be in a position"; inchoative "get into a position" and agentive "put into a position" (see also Levin 1993). From 
the discussion of the Likpe data it should be clear that the individual verbs can be said to belong to more or less all the types. In fact, what distinguishes the types in Likpe is the construction in which the verbs participate. Thus the stative locative constructions especially the BLC are used to code the 'be in a position' type. The "get into a position" pattern can be related to the agentive transitive construction while the "put into a position" pattern can be related to the three-place and the serial verb constructions. The other (nonagentive) transitive construction - the Theme-Locative construction - which signals that a Figure entity is in a position due to prior action, does not seem to fit well into any of Talmy's types. The important point, however, is that it is futile to try to classify the verbs according to the types Talmy proposes since they can all be used in that way. It is more fruitful to identify the constructions and the possibility of occurrence of the verbs in them.

In a constructional approach (e.g., Goldberg 1995), verbs can participate in constructions because their semantics allows it, or because the constructional semantics licenses them. Thus the BLC in Likpe can license a nonlocative verb to occur in it generating a stative locative configurational interpretation. A case in point is the action or separation verb siabe 'chop, hack' used in the BLC in response to a "where-search" question to localize an axe (hacked) in a tree trunk or log (CONT 29). The response is given in (20a).

$$
\begin{aligned}
& \text { a. ke-fiebi siabe lá u-yibi asúá } \\
& \text { CM-axe hack LOC CM-tree surface } \\
& \text { 'The axe is hacked in the tree' }
\end{aligned}
$$

Even though this verb, siabe 'chop, hack', is used in an instantiation of the BLC, I do not consider it a member of the form class of the contrasting locative verbs: its semantics is not primarily locative nor stative and it does not share other properties of the form class of locative verbs. For instance, it does not occur in the "where-search" question. Its use in (20a) is licensed by the construction rather than by the lexical verb. In the remainder of the paper we will discuss the semantics of the individual verbs and the way they behave with respect to the constructions we have identified.

\section{The meaning and use of the verbs}

\subsection{The general topological verbs}

The focus of this section is on the three verbs that lexicalize the general topological meanings of containment, kpé 'be.in', contact and support 
táká 'be.on' and coincidence tó 'be.at'. Some comments will be appended on the marginal $f i$ 'be.near' verb.

4.1.1. kpé 'be.in'. The verb kpé 'be.in' is used to localize entities in contained spaces - be they concrete or abstract, animate or inanimate. Thus it is used in localizing moveable inanimate Figures in containers such as 'box in purse' (TRPS 14) or 'tomato in a bowl' (TRPS 2) or 'spoon under napkin' (TRPS 24). In these scenes, parts or the whole of the Figure entity are contained in and touching part of the reference object. The verb is also used in situations where the Figure is surrounded by, but no part of it is touching the physical parts of the reference object. This is illustrated with the response to the "where-search" question with respect to the locative scenario of a 'house within a fence' (TRPS 60) in (20b).

$$
\begin{aligned}
& \text { b. di-yó nó-mó kpé li o-kpó ká.fó } \\
& \text { CM-house AGR-DET be.in LOC CM-fence } \\
& \text { 'The house is within the fence' }
\end{aligned}
$$

(TRPS 60, VA)

Animate Figures located in contained regions are also localized with this verb and hence it was used with reference to scenes relating to 'fish in a bowl' (TRPS 32) or 'rabbit in a cage' (TRPS 54) or 'a bird in a hole in a tree' (TRPS 67).

The verb kpé 'be.in' is also used to talk about the location of abstract Figures such as disease or sickness or witchcraft in places, as in (21).
sə-sí
kpé
ló u-mo
$m-f o ́$
CM-witchcraft be.in LOC CM-village AGR-DEM
'Witchcraft is in that village'

Negative spaces or damage construed as contained in the reference object are also localized with this containment verb. Thus a 'hole' in a towel (TRPS 18) elicited the response in (22) in answer to the "where-search" question.
di-bia
kpé lí le-fianku
CM-hole be.in LOC CM-towel
'The hole is in the towel'

Whenever the verb kpé 'be.in' is used and the reference object is clearly a container, then the containing region postpositions need not be used. This is because the information of containment is in the verb and the verb plus the reference object make the relation clear. This is the case in (21) and (22). 
There are spatial scenes, however, for which the verb kpé 'be.in' is used where the reference object is not a prototypical container. In such cases various postpositions are used to specify the active zone of the reference object which is being viewed as the region containing the Figure. One such scenario is where the verb is used to localize entities in open spaces under something such as 'ball under chair' (TRPS 16), characterized as (23).

\section{bólu á-má kpé lá le-kpomé ká.lo}

ball AGR-DET be.in LOC CM-chair under

'The ball is under the chair'

The space under the chair is construed as a container for the ball. However, if the space under the chair is viewed as the floor or the ground then the verb tó 'be.at' is selected instead.

Another context where appropriate postpositions are required is in the localization of Figures attached to their reference objects. Attachment scenes represented by 'pendant on chain' (TRPS 57), 'handle on a door' (TRPS 61) and 'handle on purse' (TRPS 66) are viewed as containment hence the verb kpé 'be.in' is used to talk about their location. It could also be argued that for these attachment scenes, the containment feature of the verb is not profiled and it is interpreted as signaling the location of the Figure in relation to the reference object. A similar argument could be advanced to account for the use of the verb with another type of attachment scenes: adornments and clothing on the body, e.g., 'shoe on foot' (TRPS 21), 'necklace on neck' (TRPS 54), 'cigarette in moth' (TRPS 39) and 'ring on finger' (TRPS 10), see example (15), repeated here for convenience.

$$
\begin{aligned}
& \text { le-súkpe kpé wo li ló-nimí } \\
& \text { CM-ring be.in 3SG LOC CM-finger } \\
& \text { (lit.: 'a ring is on him/her at a finger') } \\
& \text { 'S/he has a ring on the finger' }
\end{aligned}
$$

The only difference between the two types of attachment scenes is that in the case of the adornments etc. on the body, the verb occurs in an external possessor construction. But the unifying feature of the two types of attachment is that they all involve part-whole relations - the Figure being the part and the Ground being the whole. Thus the verb kpé 'be.in' is used to talk about locative situations or configurations involving containment and part-whole relations.

It has been indicated that the verb kpé 'be.in' occurs in several stative constructions: the BLC, the external possessor, the predicative possessive and the existential constructions. The verb also occurs in agentive 
transitive and ditransitive as well as serial verb constructions. In these agentive contexts, it has an active caused locative interpretation and tends to be glossed as 'put.in' as in its use in a two-place imperative construction in (24a).

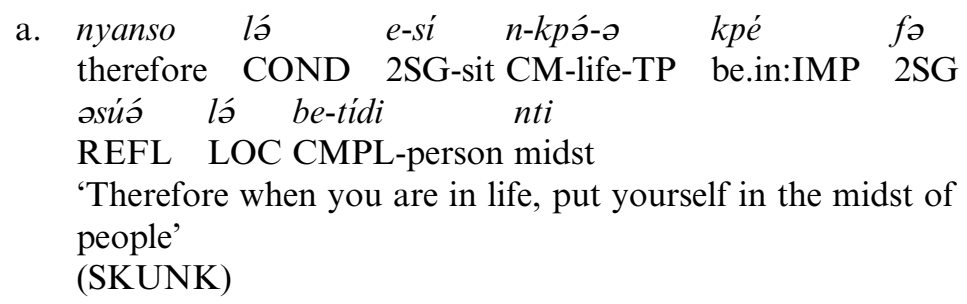

Similarly, when the verb is used in an SVC or a double object construction it has a caused locative interpretation. One context of use where the containment feature of the verb and its caused locative readings in transitive constructions is evident is when it is used to talk about planting. The verb is used to describe the process of putting cuttings or seedlings of plants such as plantain or palm fruit seedlings and cassava stick cuttings into the ground so that they can grow, as illustrated in (24b).

$$
\begin{aligned}
& \text { b. o-kpe abladzo / agbeli } \\
& \text { 3SG-be.in plantain cassava } \\
& \text { 'She has planted plantain / cassava' }
\end{aligned}
$$

The verb kpé 'be.in' has two allolexes: a negative locative/existential $m$-bá literally 'not-come.to.be/ happen' illustrated in example (6), repeated below for convenience, and a past locative verb $k \varepsilon$ 'be.at:PAST' whose use is illustrated in (25). Notice that the form occurs in an instantiation of the BLC in this example.

$$
\begin{array}{ll}
u \text {-m-bó } & \text { ló dí-yó } \\
\text { 3SG-NEG-EXIST } & \text { LOC CM-house }
\end{array}
$$

' $\mathrm{S} / \mathrm{he}$ is not at home'

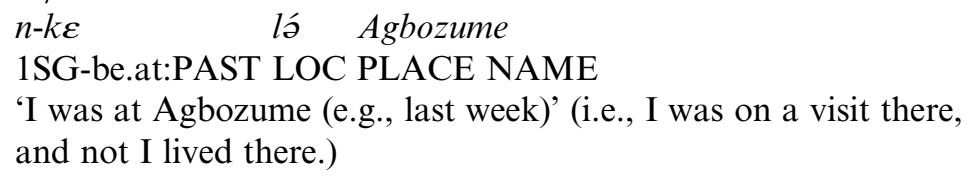

In sum, the verb kpé 'be.in' is a containment verb used for locative situations involving enclosure and part-whole configurations. When it interacts with the meanings of the constructions in which it occurs as well as the meanings of the specific lexical items that instantiate the constructions in context, various contextual readings such as 'be.at', 'put.in' or 'plant' are generated. It has two alternate lexemes: one for negation and the 
other for past time reference. The verb kpé 'be.in' itself cannot be used to express past location in a place, live or used to live in a place or negative location.

4.1.2. The contact support verb táká 'be.on.surface'. This verb is used to describe a locative configuration where a Figure is in contact with and supported by a surface on the horizontal plane. The verb does not say anything about the features of the Figure. The supporting surface of the Figure can be a smooth flat one such as the top of a table (TRPS 1), as in example 7 repeated below, the top of a desk, e.g., 'pen on desk' (TRPS 59) a shelf, e.g., a book on shelf - and it does not matter what the orientation of the book is: it could be standing on its edge (TRPS 8), or on the smallest side or lying on its side, or on one or both of its covers opened on the shelf, the same verb is used.
kópu ว́-mó
tóká
lá o-punu
osúá
cup AGR-DET be.on.surface LOC CM-table surface lit.: 'The cup is on the surface of the table'

The surface could also be less smooth like a rock, e.g., bottle lying on rock (PSPV 26) or the upper surface of a tree stump. For instance, the verb is used in the localization of a 'cassava on tree stump' (PSPV 23) and 'cloth folded on tree stump' (PSPV 34). The surface can also be created by liquid such as the upper surface of a river or ocean. Thus the verb is used to talk about the location of a boat on river (TRPS 11) or a leaf on the surface of water. The surface can also be created by (hot) charcoal as when yam tubers or cassava are placed on them to roast them. The only surface that did not elicit this verb is the ground (earth) or the floor (of a room). For localizing things on the floor or the ground, the verb to 'be.at' is used (see Section 4.1.3).

The verb tókó 'be.on' is used with both animate and inanimate Figures. Some of the scenarios involving animate Figures for which the verb is used are 'man (standing) on roof' (TRPS 34), 'a bird (perched) on a tree branch' (SUP 26) or a 'girl (standing) on a tree branch' (SUP 28), which was characterized as:

$$
\begin{aligned}
& \text { u-sío.bi á-má tóká lá u-yi á-má } \\
& \text { CM-girl AGR-DET be.on LOC CM-tree AGR-DET } \\
& \text { 'The girls is on the tree' }
\end{aligned}
$$

The relevant feature for the use of the verb is for the Figure and the reference object to be touching and in contact at some surface. The relevant Figure's active zone need not be fully in contact with the Ground. It may only be partially touching it. Thus the verb is used with respect to locative 
scenarios where only parts of the Figure are touching the edge of a basket. Thus cloth folded and located across the mouth of basket (PSPV 24) as well as a rope coiled and placed across the mouth of basket (PSPV 19), a strip of cloth dangling from the side of a basket (PSPV 16) and a stick leaning against a basket and touching only one edge of it (PSPV 13) are all said to be in a tókś 'be.on' configuration with the basket. The utterance in (27) is how 'stick leaning against basket' (PSPV 13) is localized.

u-yi á-mó tóká ló li-tsyitsya etó ko-tosi
CM-tree AGR-DET be.on LOC CM-basket POSS
'The stick is on the edge of the basket'

In all the situations discussed so far, the Figure can be easily moved away from the reference object. However, the verb is also used in the localization of Figures that are permanently fixed to the reference object in some way. Thus it is used to localize certain parts of the body with respect to the surface where they are located, for example, a nose is construed as located on the face, and eyes are viewed as being located on the head (surface). Furthermore, configurations involving Figures that are firmly fixed to their reference objects such that they cannot be easily detached from them are classified as tókś 'be.on' relations. Thus the Figure entities in spatial scenes represented by 'head (embossed) on a stamp or a coin' (TRPS 20) or 'letters or writing on a shirt' (TRPS 68) are localized using the verb. Similarly, 'a stamp on a letter' (TRPS 3) and butter smeared on knife (TRPS 12) are also classified as táká 'be.on' configurations. However, when these scenarios involving firm attachment between the Figure and the reference object are viewed as stuck to adhesive relations they may be localized using the verb má 'be.fixed, pasted, griped' (see Section 4.4).

The verb tóká 'be.on' as noted earlier occurs in both stative and nonstative constructions. It occurs in the BLC e.g., (27), in the predicative possessive construction, as in example (12), repeated below, and also the agentive constructions such as the SVC, as in (28), and the double object construction as in example (18), repeated below.

(12) (Predicative possessive)

$\begin{array}{lll}\text { kópu ó-mó tóká kú-tsye } \\ \text { cup AGR-DET be.on } & \text { CM-crack } \\ \text { 'The cup has a crack' } & \end{array}$

(18) (Double object construction) u-tóká le-bo nó-mó le-siabi 3SG-be.on CM-pumpkin AGR-DET CM-knife 'He put a knife to the pumpkin' 
(28) (Context: a child brings food in a basket to the dining table and the father instructs him to take the food out of the basket and lay it on the table.)
lókə
ə-tókə
remove:IMP 2SG-be.on
'take (it) out and put on (table)'

In the agentive constructions, such as (28), the verb has a caused locative reading and in an agentive transitive construction when its complement is a plant, such as bi-sí 'yam', it has the interpretation of 'to plant (yams)'.

Like the containment verb kpé 'be.in', the contact support verb tóké 'be.on' has both stative and nonstative readings. It is used to characterize configurations that involve contact and support (from below) and firm attachments as well as permanent part-whole relations. In all these cases, the Figure is construed as being in contact on a surface with the reference object.

4.1.3. The verb tá 'be.at'. The verb tá 'be.at' is used to signal the topological relation of coincidence. As indicated earlier, it is mainly used in the localization of nonhuman Figures. Thus when someone reports that there is a snake and is asked about its location, she responded $u$-tó $m f o ́$ [3SG-be.at there] 'It is there'. It is a general locative verb and when entities are construed as being located on the ground or the floor, there is a strong preference to use this verb in talking about their location. In the topological relations stimuli elicitation tasks, the verb is used to localize a 'ball under chair' (TRPS 16). As noted earlier, if the ball is construed to be located in the enclosed space under the chair the verb kpé 'be.in' is used. However if the ball is perceived to be located on the ground or floor space under the chair then tó 'be.at' is selected. Significantly, the tó 'be.at' verb was elicited for all the scenarios in PSPV involving individuated entities (as Figure) placed on the ground (earth). Thus 'ball on ground' (PSPV 7), 'six (three big, three small) balls on the ground' (PSPV 39), and a pot lying on its side on the Ground next to a tree stump (PSPV 40, see example [29]) are all localized with the verb tó 'be.at'.

$$
\begin{array}{ll}
\text { li-kplibi } & \text { nó-má tó ló li-kubíku } \\
\text { CM-pot } & \text { AGR-DET be.at LOC CM-tree.stump } \\
\text { ná-má } & \text { e.flo }
\end{array}
$$

AGR-DET near

'The pot is near the tree stump'

The verb tá 'be.at' has not been found to occur in agentive contexts. Thus it does not have caused locative readings. It occurs however in the stative 
constructions including the two-place predicative possessive construction as in (30).

(30) sigareti tó wo
cigarette be.at $3 \mathrm{SG}$
'He has cigarette'

The verb tá 'be.at' expresses topological coincidence and is highly favored in localizing entities that are placed on the ground or the floor. It is the purest of the verbs in stativity since it does not occur in any of the agentive constructions.

4.1.4. The propinquity verb fi 'be.near'. The verb $f i$ 'be.near' as pointed out earlier, is rather marginal. It is included here for the sake of completeness. Example (5), repeated below, was given as a second response in localizing 'dog in kennel' (TRPS 6). The first response offered involved the posture verb $s i$ 'sit' and a Ground phrase using the postposition e.flo 'near', as in (31).

$$
\text { o-kpâ á-má sí lí wo dí-yó e.flo }
$$

CM-dog AGR-DET sit LOC 3SG CM-house near

'The dog is (sits) near its house'

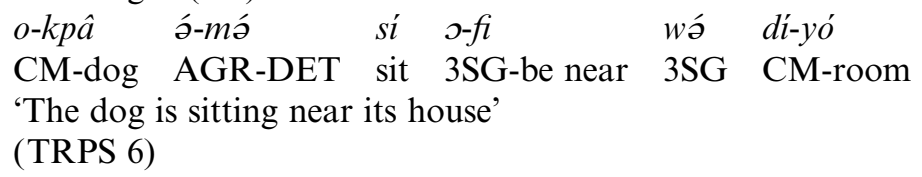

It appears that for relations of propinquity, speakers prefer to use the postposition e.flo 'near' together with an appropriate configurational verb rather than the propinquity verb $f i$ 'be near'. This may be the reason why it is rather marginal.

\subsection{The postural verbs}

4.2.1. The verb si 'sit'. The verb si is used to characterize the canonical state of an animate entity on its base supported from below by a surface. It is used to describe the sitting posture of humans in situations such as those represented by 'a person straddling a wall' (SUP 31) or 'a person sitting on a wall' (SUP 32). In both scenarios the Figure is localized using the utterance in (32). The verb is also used in relation to animal Figures as well, such as a 'cat (on its hind) under table' (TRPS 31) or a 'dog in basket' (TRPS 47). 


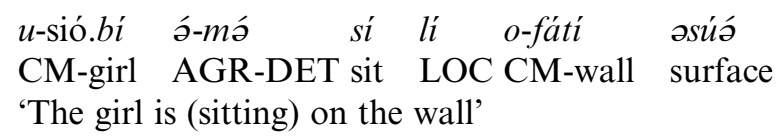

The verb is also used to localize human entities in a place irrespective of their posture. In this usage it has the interpretation of the person living or being settled in that place. Thus the present author can say the expression in (33a) about himself, since he resides in the Netherlands. In the use of the verb si 'sit' with the reading of 'living in a place' which implies a more or less permanent location, it contrasts with the use of the verb kpé 'be.in' to signal general location, which implies a more temporary location. This is the contrast between (33a) and (33b) where the latter implies that the speaker is not resident in the Netherlands but was there for a visit for a short time.
a. n-sí ló Holland
1SG-sit LOC Netherlands
'I live/reside/stay in the Netherlands'
$\begin{array}{lll}\text { b. } & n-k p e ́ & \text { lá Holland } \\ \text { 1SG-be.in LOC Netherlands }\end{array}$
'I am in the Netherlands (at the moment)'

The verb si' 'sit' has an allolexical form sio which is used as the agentive and transitive counterpart of $s i$ 'sit'. It is commonly heard in imperatives such as siə ká-so 'sit ground', i.e., 'sit down' and siə le-kpomé 'sit (on the) chair'. The sio 'sit, settle' form is also used as the nonpresent counterpart of $s i$ 'sit'. Thus to express the idea that someone lived or settled in a place in the past the sia 'sit, settle' form is used, as in the following extract from a text about the migration history of the Likpe people.

$\begin{array}{llll}\text { bó } & \text { ba-kpelé } & \text { lá bó kə-siə-kó } & \text { fefe } \\ \text { 1PL } & \text { CMPL-Likpe } & \text { TP 1PL CM-sit-place } & \text { last } \\ k a & \text { buu-siə } & n i \quad \text { atébubu } & \\ \text { AGR 1PL:POT-sit } & \text { COP A. }\end{array}$

'We the Likpe our last place where we settled was Atebubu'

Notice that in example (34) the sio 'sit, settle' verb form is used in a two place construction as well as referring to the past. In fact, as a verb it is also the input to a location nominalization in the word kə-siə-k5 ' $\mathrm{CM}$-sitplace', i.e., settlement. ${ }^{4}$

Just as the verb si 'sit' has a more permanent implication in comparison with kpé 'be.in' when they are used with respect to the location of humans in a place, so does siə 'sit, settle' also implicate a more permanent settlement in comparison to $k \varepsilon$ 'be.at:PAST', the past counterpart of kpé 'be.in'. 
The verb si 'sit' does not seem to be used in the localization of moveable inanimate Figures. The only inanimate referents I have found functioning as Figure with the verb are places and place names, as in (35).

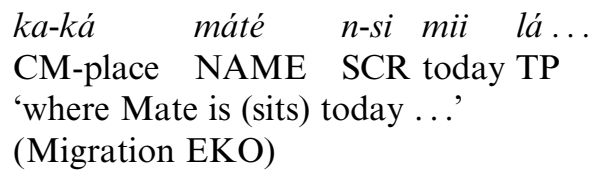

Thus the verb si 'sit', apart from being used to talk about the posture of humans and animals, is also used to describe the general location of people and places. It has a transitive nonpresent counterpart which is also used to express caused-locative meanings.

4.2.2. The verb nyə 'stand'. The verb nyə 'stand' is used for living things when they are in a relatively upright position with respect to a horizontal plane. Thus it is used to localize humans, e.g., 'man on roof' (TRPS 34), animals (e.g., chickens) and plants, e.g., 'tree in front of a church' (TRPS 49). It is also used with inanimates especially structures that are erected, e.g., 'poles fixed in the Ground' (PSPV 20) or a fence (TRPS 15). In the context of picture stimulus elicitation the fence, as Figure, is asked about using the verb, as in the utterance in (36).

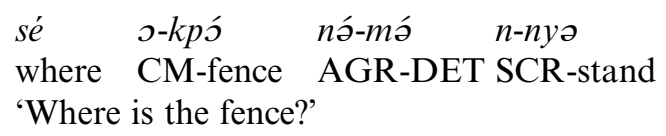

When the verb is predicated of inanimates it may sometimes have an existential reading. In example (37) there are two uses of the verb in two clauses. In the first clause, the verb seems to be used with an existential reading when predicated of di-yó 'house'. In the second clause, the verb is used with respect to a human and has a stative locative (postural) reading.

$$
\begin{aligned}
& \text { dí-yó e-bú-nyə tsyáa e-bú-nyə } \\
& \text { CM-building SCR-FUT-stand too 2SG-FUT-stand } \\
& \text { lá le-kple o-somí blé fə } \\
& \text { LOC CM-outside CM-rain beat 2SG } \\
& \text { 'There will be a house but you will be (standing) outside and be } \\
& \text { rained upon' }
\end{aligned}
$$

Note that the two clauses also differ in structure. In the first clause there is no complement or adjunct to the verb - an instantiation of a one-place construction. The second clause is an instantiation of the BLC where the verb takes an obligatory locative adjunct. 
Where the Figure is firmly fixed to the ground and in an upright position (and consequently perceived to be immoveable) the only verb that is used to characterize such a configuration is the verb nyo 'stand'. In such cases, it seems the orientation of the Figures is profiled. Thus 'tree on hillside' (TRPS 17), 'tree in front of church' (TRPS 49) and building /house within fence' (TRPS 49) are all localized with this verb. Similarly bottles which are planted in the Ground are also localized with this verb. For instance, the verb is used with respect to PSPV 28 where three bottles are fixed in the ground with two upside down. This shows that for such objects it doesn't matter whether they are in their canonical or noncanonical orientation. The relevant response is given in (38).
a-bodiambo
nyã-má
nyá lá ká-só
$n t i$
CMPL-bottle AGR-DET stand LOC CM-Ground midst
'The bottles are (fixed upright) in the ground'

For several locative scenarios there is variation among speakers related to the choice of a general topological verb like tóké 'be.on' and kpé 'be.in' or the more specific postural verb nys 'stand'. For the scenario involving 'man on roof' (TRPS 15) half the respondents gave tók 'be.on' as the first response and nyə 'stand' as the second response. The other half also gave the two verbs but in reverse order. Similar responses were obtained with respect to 'bottle (upright) on rock' (PSPV 10). Concerning the localization of 1 bottle standing in a basket, the majority of the consultants gave nyá 'stand' in their first responses and used kpé 'be-in' as a second response. The motivation for the variation seems to relate to what the speaker perceives as the salient configuration. Where the posture verb is chosen, the speakers tended to be attending to the orientation of the Figure more than the overall topological relation.

For its causative use, the verb nyo 'stand' can either take the causative suffix nyə-n-sə [stand-LIG-CAUS] 'cause to stand' or be used in an SVC as the noninitial verb to signal the resultant state of the action of the first verb. For instance, to instruct someone to stand up, one says táka ə-nyə 'rise:IMP 2SG-stand', i.e., 'get up and be in a standing position'. The verb can also be thought of as the resultative counterpart of some of the uses of an action verb sé 'fix, erect'. The action of fixing or ramming poles, palm fronds etc. into the ground is described using this verb sé 'fix, erect', but once they have been put in the Ground and are upright then they are characterized with the verb nyə 'stand'. ${ }^{5}$

4.2.3. The verb labe 'lie'. The verb labe 'lie' is typically used of animates - humans and animals. It characterizes entities that are in an elongated horizontal position with their whole body. It is thus used to 
localize a 'tiger lying on a tree branch' (SUP 27) or a child lying in their bed. With humans, the verb has the added sense of 'sleep' which is metonymically linked to it (i.e., something one does when one is lying down). Because of this extended sense, the verb is used in "how-are-you" greeting questions and also in good night expressions. Thus at night one can wish sound sleep to one's interlocutor by saying: labe kpóo 'lie quietly', i.e., sleep soundly! And in the morning, as part of the greeting ritual one can ask: á-labe kpóóo [2SG-lie quietly-Q], i.e., 'Did you sleep well?'

The use of the verb with inanimate entities is rather marked. In fact speakers rejected the verb labe 'lie' for inanimate Figures that are clearly in an elongated horizontal position, that is, entities that are clearly "lying" on a surface such as 'pen on desk' (TRPS 59), one or more tubers of cassava lying on tree stump (PSPV 23, PSPV 43), one 'bottle lying on a rock' (PSPV 26) or on a table (PSPV 37) or several bottles (7) all lying on a table (PSPV 52), a stick lying across a table (PSPV 17) or across a basket (PSPV 43). All these configurations were categorized as tókś 'be.on' relations, and speakers explained that the verb labe 'lie' was unacceptable because the Figure entities involved are inanimate.

However, there are contexts in which the verb labe 'lie' is spontaneously used with inanimate Figures. One context, as noted earlier, is when speakers want to show contrast among multiple Figures in terms of their orientation or position. As suggested earlier this seems to be the motivation for the localization of the Figures in PSPV 46, three bottles standing and four lying on a table as shown in example (2a), repeated here for convenience.
a. o-tsywá
nyə
$a-n a$
labe ló o-punu
osúá
AGR-three stand AGR-four lie LOC CM-table surface 'Three are standing, four are lying on top of the table'

Another context in which the verb labe 'lie' is predicated of inanimate entities is when it is used to describe the resulting position that an entity falls into. This context also involves contrast with other possible positions. In this context, the verb occurs as a second verb in an SVC in which the first verb describes the action that makes the entity assume the position represented by the second verb. Consider a second response to the "where-search" question stimulated by a picture of a pot on its side, next to and touching a tree stump (PSPV 40) given in (39).

$$
\begin{aligned}
& \text { li-kplibi nó-mó o-tú le-labe lá li-kubiku } \\
& \text { CM-pot AGR-DET SCR-fall 3SG-lie LOC CM-tree.stump } \\
& \text { nó-mó e.flo }
\end{aligned}
$$

AGR-DET near

'The pot fell over and lies near the tree stump' 
The verb labe 'lie' is thus restricted to contrastive contexts in the localization of inanimate Figures. For animate Figures, it is used to characterize their location in an elongated position. The verb labe 'lie' could be seen as a rather specific counterpart to the more general locative verb tóḱ 'be.on'. Given that inanimate Figures that are in an elongated position are localized with this verb, and even the multiple Figures with mixed orientations are localized with this verb tókś 'be.on', we can conclude that the orientation of the Figure is less salient than the configuration for Likpe speakers in the localization of inanimate Figures.

4.2.4. The 'hang' verbs fáka and yóma. There are two verbs in Likpe for talking about Figures attached to their reference objects by suspension, namely, fáka and yóma. The more frequent of the two is fáka and it is used to characterize locative relations involving point suspension where the Figure is not supported on any other part or side. Thus it is used in localizing 'coat on hook' (TRPS 9), 'apple on branch' (TRPS 27) or 'apples on tree' (TRPS 45), 'rope hanging from tree' (PSPV 33) or 'cloth dangling from tree' (PSPV 59), 'lamp from ceiling' (TRPS 63), see example (9), repeated below, and 'clothes on line' (TRPS 45) which is illustrated in (40).

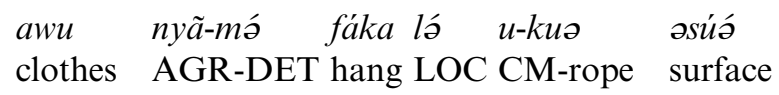
'The clothes are hanging on the line'

(9)

o-kanía fáka lí o-púnú ó-mó eto
CM-lamp hang LOC CM-table AGR-DET POSS
ka-tó
CM-up/heaven
'The lamp is hanging above the table'

The prototypical schema for the verb fáka 'hang, point suspension' is something attached at a point to a reference object in a string-like fashion. This may be the schema that underlies the use of the verb as an alternative to the verb kpé 'be.in' in the localization of 'handle on purse' (TRPS 61). The verb is also used for situations in which the Figure is attached at a point without suspension such as 'hooks in wall' (TRPS $50)$.

The verb fáka 'hang, point suspension' is also used to characterize spatial scenes where there is no contact between the Figure and the reference object, rather the Figure is located above the reference object (in the air). Thus it is used to localize 'light over table' (TRPS 13) and 'cloud over mountain' (TRPS 36), for which the response is shown in (41). 
(41)
o-lóku
fáka lá ko-tini
kó-mó
eto ka-tó
CM-cloud hang LOC CM-mountain AGR-DET POSS CM-sky 'The cloud is over the mountain'

The verb fáka 'hang' can be morphologically causativized and used in a handling SVC to express caused location, as in (42).

$$
\begin{aligned}
& f i \quad \text { kótu ó-mó a-fáka-sá lí pégi } \\
& \text { take:IMP coat AGR-DET 2SG-hang-CAUS LOC peg } \\
& \text { 'Take the coat and hang it on the peg' }
\end{aligned}
$$

In fact, even without the morphological causative marker the verb can be used in an agentive transitive construction, as in the following instantiation of the external possessive construction signaling the endpoint placement of the Figure in a part of the possessor's body.
di-kubi
a-fáka
me lá o-kóe
CM-bone SCR-hang 1SG LOC CM-neck
'A bone is lodged in my throat'

All the uses of the verb fáka 'hang' involve attachment at a point and, prototypically, suspension from that point. The uses of the second 'hang' verb in Likpe - yóma - also involve attachment at a point with the added feature that there is partial support or contact between parts of the Figure and parts of the reference object (beyond the point of suspension). In fact, in generating utterances elicited with the picture stimulus in PSPV 59 where a strip of cloth is thrown into a tree-one part is suspended from a branch and another part goes over the branch before dangling down from it, both verbs are used, as illustrated in (44).

$$
\begin{aligned}
& \text { ka-fia eto o-le ó-mó fáka ló o-le } \\
& \text { CM-cloth POSS CM-part AGR-DET hang LOC CM-part } \\
& \text { osúá o-le o-ní tsyâ yóma } \\
& \text { surface CM-part AGR-one also hang } \\
& \text { 'A part of the cloth is suspended from the branch (of the tree) and } \\
& \text { another part also is hanging over the branch' }
\end{aligned}
$$

The verb yóma 'hang, with partial support' is also used to localize a sheet of paper adhering partially or weakly to a pole (and about to fly away) (SUP 43, 44). In such scenarios the Figure is attached at a point and then part of the reference object supports it but not completely. The contrast between the two hang verbs can be appreciated when one compares the following scenarios involving the same referent as Figure - a string - attached to different reference objects yielding slightly different locative relations. In one scenario a string is hanging on a nail (SUP 37). For 
this scenario, the verb fáka 'hang, point suspension' is used (see example [45a]). In the other scenario, a piece of string is placed on an arm of a pair of scissors and dangling but touching the blade (SUP 45). For this scenario the verb yóma 'hang, attached with partial support' is used to localize the string (see example [45b]).
a. u-kuá fáka li se-lakabi asúá
CM-rope hang LOC CM-nail surface
'The string hangs from the nail'
CM-rope hang LOC scissors POSS CM-tooth
'The string hangs from the blade of the scissors'
b. u-kuó yóma li kampe eto kó-ma

Thus Likpe has two verbs for talking about locative relations involving attachment at a point. The difference between the two verbs lies in whether the configuration involves suspension of the Figure from the point of attachment without any further support or it involves some further support of the Figure from the Ground. It is not unusual for a language to have more than one verb for 'hang' focusing on different gestalts of a hanging situation (cf. Liu [2003] who describes three verbs for 'hang' in Mandarin).

4.2.5. The verb kpásá 'lean'. The verb kpásá 'lean’ has a complex morphological make-up as it has the morphological causative -só as an integral part of it. It is not clear what the source of the other syllable $k p$ s is. It could be related to the containment verb kpé 'be.in' where the schwa of the causative morpheme assimilates the 'e' vowel in kpé to be more like it.

Be that as it may, the verb kpósá 'lean' is used to characterize leaning locative relations. That is, relations in which the Figure is in contact with the reference object at one point and it is supported at another point external to the reference object but orthogonal to it. Thus the Figure has to be at an angle in relation to the reference object and the Figure has to be rigid and solid. In the description of the stimuli used in the elicitation for this study, the verb is used in localizing 'ladder against a wall' (TRPS 58) or a 'stick against a tree' (PSPV 1) or five tubers of cassava against a tree stump (next to and touching it) (PSPV 65), as illustrated in (46).

agbeli nyã-má kpá-sá lá li-kubiku

Cassava AGR-DET lean LOC CM-tree.stump

nó-mó osúá

AGR-DET surface

'The tubers of cassava are leaning against the tree stump' 
One scenario in the stimulus pictures that fits the gestalt of the locative relation described for the verb kpásá 'lean' above but for which the verb is rejected is 'stick leaning against basket' (PSPV 13). The verb tókś 'be.on' is the one used to localize the stick in this case (see example [27], repeated below for convenience).

$$
\begin{array}{lllll}
\text { u-yi tóḱó lá li-tsyitsya etó } & k o \text {-tosi } \\
\text { CM-tree AGR-DET be.on } & \text { LOC CM-basket POSS } & \text { CM-edge }
\end{array}
$$

'The stick is on the edge of the basket'

This may point to another feature that is relevant for the kpásá 'lean' verb. It appears that the reference object has to be higher than the point at which the Figure makes contact with the reference object. In the scenario under discussion, the stick makes contact with the edge of the upper edge of the basket and goes over it. This may be the reason why kpásá 'lean' is inappropriate for its characterization. Nevertheless, it also indicates an overlap between tóká ‘be.on' and kpósá 'lean' relations involving general vs. specific forms of support. This could lead to the more specific situations being characterized more and more by the general verb.

4.2.6. The verb fusá 'squat, be.upside.down'. The verb fusá 'squat, be.upside.down' is another element that has the morphological causative lexicalized with it, but for which there is no clear source of the root form. The verb is used to characterize the crouching or squatting of animates. In the pictures that were used as stimulus for the elicitation, the positions of some animate entities were viewed as one of squatting. So the 'boy behind a chair' (TRPS 64), as in example (47), and 'dog in kennel' (TRPS 71) were both localized with this verb.

li-kpefi ná-má fusá lá le-kpomá káma
CM-child AGR-DET squat LOC CM-chair back
'The child squats behind the chair'

The verb fusá 'squat, be.upside.down' is used with inanimates that are turned upside down. In the topological relations tasks on which this study is based, the verb was used to localize 'a pot upside down on tree stump' (PSPV 12) and a 'pot upside down hanging in tree' (PSPV 29). For both scenarios however, the verb fusá ‘squat, be.upside.down' was offered as a second response. The preferred response for 'pot upside down on tree stump' (PSPV 12) is tóké 'be.on' and for 'pot upside down in tree' (PSPV 29) is kpé 'be.in'. This indicates that in the localization of entities that are upside down, the orientation of the Figure is less important and less salient than the overall Figure-Ground configuration. In a sense this 
verb could be said to be rather marginal when it comes to the localization of inanimate entities.

It is less marginal and more frequent with respect to a cultural practice associated with the domestic keeping of chickens. The practice relates to keeping chickens under baskets especially when there is no coop or when they are newly acquired. In this context one often hears the verb in relation to the inanimate Figure, basket. Children are regularly asked to take a basket to cover the chickens using a handling serial verb construction like the one in (48).

$$
\begin{array}{lllll}
f i & \text { li-tsyitsya } & \text { e-fusá } & \text { ló } & \text { wo } \\
\text { take:IMP } & \text { CM-basket } 2 \text { SG-squat } & \text { LOC } & \text { 3SG }
\end{array}
$$

'Take the basket and cover it' (i.e., take the basket and put it upside down over it)

Apart from such a usage, which has a causative overtone, I have not yet encountered the verb in transitive structures nor in the double object construction.

\subsection{Verbs of "distributed" configuration}

4.3.1. The verb tí 'be.covered'. The verb tí 'be.covered' seems to be used only in localizing inanimate Figures. It is used in situations where the Figure is attached to the reference object in more or less a tight fit relationship. The fit can be very tight as for 'cork in bottle' (TRPS 62) which elicited the response given in (49).
e-ti-n-sá
$t i$
lá li-tuntu

CM-cover-LIG-thing be.covered LOC CM-bottle

'The cork covers the bottle'

A similar tight fit is involved in the relation between a hat and the head when it is worn on it; hence the verb is used in the localization of 'hat on head' (TRPS 5). In this case being an adornment on the body, the verb is used in the external possessor construction as in (50).

$$
\begin{aligned}
& \text { le-kpakpa tí wo lá li-sí } \\
& \text { CM-hat be.covered 3SG LOC CM-head } \\
& \text { 'A hat is worn on his head' }
\end{aligned}
$$

The difference between the tight-fit relationship as a feature of the verb $t i$ 'be.covered' and contact relationship represented by the verb tók 'be.on' is reflected in the fact that if a hat was not worn but was just placed on the head, the verb $t i$ 'be.covered' is rejected and the contact verb is accepted. 
Similarly, if a cloth covers a table in a tight-fit manner as in (PSPV 14) or (TRPS 29) then the verb $t i$ 'be.covered' is used to localize the Figure as illustrated for (TRPS 29) in example (16). However if the cloth is just placed on the table without any fit, i.e., just in contact with the table surface, then the contact and support verb tók'́ 'be.on' is favored.

As indicated in Section 3, the verb $t i$ 'be.covered' occurs in agentive transitive constructions as well as SVCs.

4.3.2. The verb kpó 'be.spread, heaped'. The verb kpó 'be.spread, heaped' is used to characterize locative relations in which the Figure cannot be easily individuated. It is thus used with respect to a mass of particles or particle-like entities, liquids, flexible objects that are spread in a place or a multiplicity of countable items that are in a heap. In the elicitation task, it is used to localize beans on ground (PSPV 11) or on table (PSPV 25), 'rain drops on window' (TRPS 48) or 'cloth spread in and over a basket' (PSPV 16).

Similarly, the verb is used with respect to individuated items such as bottles or tubers of cassava when they are construed as being in a heap and being unindividuated. It is thus used in the first response to localize four tubers of cassava lying on the ground (PSPV 42), seven tubers of cassava lying on top of each other (PSPV 51), five tubers of cassava lying in a basket (PSPV 53) and seven bottles jammed in a basket in different orientations (PSPV 60). Example (51) is the response offered in relation to PSPV 51:
a-gbeli
nyã-mó
$k p o ́$
lá ká-só
CMPLcassava AGR-DET be.heaped LOC CM-Ground
'The tubers of cassava are (heaped) on the ground'

Given that the verb is used with mass Figures, it tends to be translated as 'pour' in caused locative structures as illustrated earlier in example (17), repeated below.

$\begin{array}{llll}\text { Sáka } & a-k p o ́ & n-t u & \text { l' tánki } \\ \text { NAME } & \text { SCR-be.poured } & \text { CM-water } & \text { LOC tank } \\ \text { 'Saka poured water into the tank' } & \end{array}$

This is one verb for which the nature of the Figure rather than the overall configuration is salient, namely, its unindividuated nature.

\subsection{Verbs of adhesion}

There are two verbs má 'be.pasted, griped' and mánkla 'be stuck to, be fixed to tightly'. ${ }^{6}$ The verb má 'be.pasted' occurs in a wider set of contexts than mánkla 'be fixed to'. The verb má 'be.pasted' is used to characterize 
situations in which a Figure is attached firmly to a reference object so that it cannot easily fall off. The adhesion could be affected with the help of some other substance such as glue, or it could be produced from the properties of the entities involved in the configuration. In the "where-search" localization tasks, the verb $m a$ ' be.pasted' is used, for example, to localize 'spider on ceiling' (TRPS 7) and also for 'paper adhering totally to pole' (SUP 42) (see example [52]). For these scenarios all consultants used the form $m a$ 'be.pasted' as their first and only verb.

$\begin{array}{lll}k u \text {-kuá má } \quad l i \quad u-y i & \text { əsúá } \\ \text { CM-paper be.pasted } & \text { LOC CM-stick } & \text { surface } \\ \text { 'The paper is pasted on the pole' } & \end{array}$

For two other adhesive scenarios, namely, 'stamp on letter' (TRPS 3) and 'butter on knife' (TRPS 12), the contact and support relation between the Figure and the reference object can be construed to be more salient. Thus the contact verb tóká 'be.on' was selected in the first response to these stimuli. Nevertheless the verb má 'be.pasted' was also used as an alternative in the second responses to the stimuli. The verb má 'be.pasted' is also used in localizing 'creatures on wall' (TRPS 52) as well as 'gum attached under table' (TRPS 53).

The verb má 'be.pasted' occurs in agentive transitive constructions. Thus one can say $m$-má watch 'I have strapped on a watch', i.e., I have a wrist watch on. This is consistent with the feature of tight adhesion of the verb. ${ }^{7}$ The verb is used in the handling serial verb construction to express caused locations as in (53).
$u-f i$
plasta o-má
lá lé-fabé
3SG-take plaster 3SG-paste LOC CM-wound
'He placed plaster over the wound'

The verb má 'be.pasted' has not yet been encountered in a double object construction nor does it host the causative morpheme.

By contrast, the verb mánkla 'be stuck to, be fixed' can be causativized as we shall see below. The verb mánkla signals that something has been attached firmly to something else so that the attached thing cannot be easily removed. The verb mánkla 'be stuck to', like the verb má 'be.pasted', is used to localize 'creatures on wall' (TRPS 52) and 'gum under table' (TRPS 53). It seems that the difference between the two verbs is in whether the attachment configuration between the Figure and the reference object is construed as one which can be easily detached or not. Thus it appears 'spider on ceiling' (TRPS 7) is construed as an attachment which can be easily removed hence all consultants used the verb $m a ́$ 'be.pasted' for it. However, 'creatures on wall' (TRPS 52) can have 
alternate construals either as being easy to remove or not so easy to detach, hence both verbs are applicable.

An indication of the idea that mánkla 'be stuck to' has a component of the attachment being perceived as not being easy to undo is that it is used in its morphologically causativized form to describe the "attaching" of Jesus to the cross, as shown in (54).

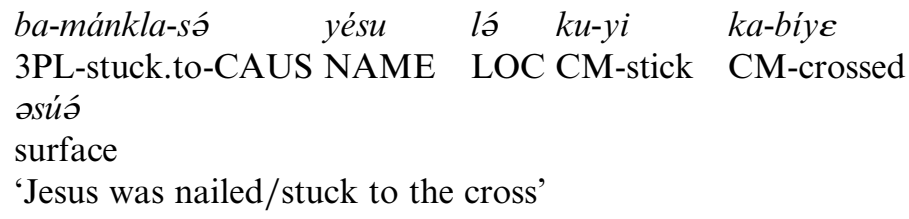

Even though the two adhesion verbs overlap, there is a difference between them mainly in terms of the ease with which the Figure and the reference object can be detached from one another.

\section{Summary}

In the foregoing, the grammar, use and meaning of a class of fifteen verbs that are used in the Basic Locative Construction (BLC) in Likpe have been discussed. It is shown that Likpe is a multiverb language with only one locative preposition and a dozen or so postpositional elements. While the verb cannot be omitted in the BLC, the locative preposition, which is also not normally omitted, tends to be left out when the reference object is an inherent locational noun such as dí-yó 'house' or ka-to 'sky, heaven'. The postpositions are more regularly omitted when the search domain can be inferred from other information in the construction such as from the semantics of the verb or of the reference object nominal.

The BLC is used for all categories on the localizability hierarchy (see Ameka and Levinson, this issue) with the exception of Level V, adornments and clothing on the body. As indicated earlier, an external possessor construction which is a modulation of the BLC is used for such scenarios. Another specific exception is the scenario involving Figure as damage. It was noted that damage as hole in something is localized using the containment verb in the BLC. However, damage as crack on something like a cup is not construed as a locative relation, rather as a possessive one and the contact support verb is used in a predicative possessive construction to characterize it (see example [12]).

The locative predication in Likpe is predominantly concerned with the overall configuration of the Figure-Ground relation and the verbs used in the BLC classify the actual configurations that entities enter into. However, I claim that there can be alternative construals of configurations 
leading to variation in the choice of the verbs to characterize particular situations. The choice is however not random, it is always related to the choice between a more general and a more specific verb. For instance, in localizing seven bottles lying on a table, a speaker can construe them as being in contact with the reference object surface and choose the 'be.on' contact verb tókś. The same speaker can also construe the configuration as one involving multiple Figures and not attend to the contact support relation between the Figure and the reference object. In this case they can choose the more semantically specific verb kpó 'be.spread, heaped'. The two choices would seem to reflect two competing pragmatic principles. The stereotypical configuration between a Figure and a reference object on a surface is that of contact. Hence the general verb reflects the stereotypically expected configuration. The choice of the more specific verb reflects a speaker's desire to be referentially more precise, i.e., to give detailed information about say the nature of the Figure in addition to the configurational information.

Even though the verbs are mostly concerned with the overall FigureGround configuration, two of them seem to have entailments that give information about the nature of the Figure. One of these is kpó 'be.spread, heaped', as just illustrated. It entails that the Figure is a mass, unindividuated. The other verb, which is very marginally used with inanimate Figures, is fusá 'squat, be.upside.down'. When it is used with inanimate Figures it means that the Figure is in upside down position.

Apart from these two verbs one can draw inferences about the nature of the referents that are functioning as Figure and Ground in particular instances from the use of some verbs. For instance, if a configuration is characterized with the general locative verb tó 'be.at' one can infer that the Figure is inanimate and that the Figure is placed on the floor or the ground. Or, if the verb nya 'stand' is used one can infer that the Figure has a vertical dimension and is in a position almost perpendicular to the Ground or the floor (or the reference object). Similarly when the 'be.on' verb tókś is used one infers that the search domain of the reference object is its surface and when the verb kpé 'be.in' is used one infers that the reference object is a container, unless one has some other evidence to the contrary, e.g., from the semantics of the postpositions used. Indeed these default inferences associated with some of these verbs (together with postpositional information) can sometimes be used to disambiguate some nominals. For example, the word $っ-k p \varepsilon$ has the two readings of 'plate' and 'bowl'. If this word collocates with the postposition for surface and with the verb 'be.on' then the interpretation of 'flat plate' is derived. However with the containment verb and a postposition designating containing region then the interpretation of '(deep) plate/bowl' is derived. 
We have also indicated that the posture verb labe 'lie' is very restricted in its use with inanimate Figures. It is only used in the particular discourse context when speakers are attending to distinctions in the orientation of the Figure entities. Additionally, it has been shown that the posture verb $s i$ 'sit' has a transitive and nonpresent counterpart and that it is used for general location without implying a specific posture.

Moreover, attention was drawn to the variation among speakers and the alternative construals that speakers display with respect to particular configurations. The difference invariably between the construals which guides the variation is that between the use of a more general semantics verb versus a more semantically specific verb. All the consultants tended to prefer the semantically general verbs to the semantically specific verbs. If this preference gets entrenched it might lead to some of the specific verbs losing their position in the form class of locative verbs and Likpe might drift more towards a Type II small set (3-7) of contrasting locative verbs used in the BLC. For instance, as noted throughout, some configurations involving contact and support between Figure and Ground can be characterized with the general topological verb təká 'be.on' or with more specific verbs like kpó 'be heaped' if they are multiple Figures (PSPV 52), labe 'lie' and nyo 'stand', if they involve contrasting orientations of the Figures (PSPV 46) and even má 'be.pasted' if there is attachment that cannot easily fall off. Similarly, firm attachment relations of things planted or fixed in the Ground or reference object, for example, can also be characterized as containment relations and described with the more general kpé 'be.in' rather than a more specific posture verb such as nyə 'stand'. Furthermore we have also noted that the 'sit' posture verb si has both a specific postural usage and a general locative usage. So there could be a more generalizing tendency going on. The outcome of such a development will be a reduction in the number of verbs that can occur in the BLC in the language. The hypothetical outcome of this might leave only the following five or six verbs for use in the Likpe BLC: táká 'be.on', kpé 'be.in', tó 'be.at', si 'sit', fáka 'hang' and má 'be.pasted'.

Such a development seems to have occurred in some of the other Ghana-Togo-Mountain (GTM) languages like Nyagbo and Logba (see Essegbey et al. 2004). In Nyagbo for instance, there are four verbs that occur in the BLC. These are: lé be.at, kpase 'be.in', tsidi 'be.on' and some 'hang'. In terms of the typology of locative predication presented in Ameka and Levinson (this issue), Nyagbo with its four verbs is a Type II language - the small closed class set of verbs - similar to the postural verb type languages like Dutch or Goemai. However, the semantics of the verbs are not all postural. There is only one posture verb and the rest correspond to the basic topological relations of coincidence, 
containment and contact and support. The Likpe system in comparison to the other GTM languages provides a window on how a multiverb language might evolve into a small-set Type II language.

Received 8 June 2005

University of Leiden

Revised version received

12 March 2007

\section{Appendix. Abbreviations}

$\begin{array}{ll}\text { AGR } & \text { agreement marker } \\ \text { CAUS } & \text { causative } \\ \text { CM } & \text { noun class marker } \\ \text { COND } & \text { conditional } \\ \text { COP } & \text { copula } \\ \text { DEM } & \text { demonstrative } \\ \text { DET } & \text { determiner } \\ \text { DIM } & \text { diminutive } \\ \text { EXIST } & \text { existential } \\ \text { FUT } & \text { future tense } \\ \text { IMP } & \text { imperative } \\ \text { LIG } & \text { ligature } \\ \text { LOC } & \text { locative (preposition) } \\ \text { NEG } & \text { negative marker } \\ \text { PAST } & \text { past tense } \\ \text { PL } & \text { plural } \\ \text { POSS } & \text { possessive marker } \\ \text { POT } & \text { potential } \\ \text { Q } & \text { propositional question marker } \\ \text { REFL } & \text { reflexive marker } \\ \text { SCR } & \text { subject cross-reference marker } \\ \text { SG } & \text { singular } \\ \text { TP } & \text { background topic marker } \\ 1 & \text { first person } \\ 2 & \text { second person } \\ 3 & \text { third person }\end{array}$

\section{Notes}

1. The sources of examples are sometimes indicated using abbreviations to identify consultants, e.g., EKO, AA or VA. In addition the titles of texts are sometimes provided and spelled in caps, e.g., SKUNK. I am indebted to the consultants on Likpe for their continued willingness to help me understand their language. I also thank two anonymous 
reviewers and James Essegbey for their helpful comments on an earlier version of this paper. Correspondence address: Dept. African Languages and Cultures, Leiden University Centre for Linguistics, PB 9515, 2300 RA Leiden, The Netherlands. E-mail: f.k.ameka@let.leidenuniv.nl or felix.ameka@mpi.nl.

2. The locative preposition is sometimes realized as vowel lengthening in fast colloquial speech, for example,
(i) le-fianku kpe-e
le-laka (ká.fó)
CM-towel be.in-LOC CM-box inside
'The towel is in the box'

3. The 'hang' verbs faka and yoma could also be classified as attachment verbs. But they are included in the postural semantic class here because they pattern more like the other posture verbs than like the attachment verbs. Also, crosslinguistically 'hang' verbs tend to be grouped with the other postural verbs like sit and stand.

4. From the discussion so far, one could be tempted to think of the schwa at the end of the verb sia 'sit, settle' as a transitivizing suffix. However, it does not seem to be a productive suffix. It has not yet been found with any other verbs. It is plausible to think of it as a lexicalization based on the verb si. In fact, the form sia 'sit, settle' feeds into other word formation processes, as just noted. It can also host the causative morpheme to derive the verb siə-sá 'greet'. The derivational relationship between the two forms is not immediately obvious. However, I suggest that they are related in the following way. First, the greeting expression that one addresses to people as if it is a time of day greeting is sia (for one person). This could literally have developed from a usage which says something like 'you are seated' building on the nonpresent form. Then it became routinized as a greeting and then the causative is added to it to form a delocutive verb.

5. The interesting thing about this verb sé 'fix' is that it can be licensed by the BLC and so be used to localize a Figure that is firmly attached to its reference object. Thus one of the responses with respect to 'stamp on letter' (TRPS 3) used this verb. The full response is:
(i) stampu sia-má sé lá envelop asúá
Stamp AGR-DET fix LOC envelope surface
'The stamp is fixed on the envelope'

6. The forms seem to be related. mánkla seems to be made up of má and another form kla linked by a nasal ligature. I have not yet found a form to relate to the kla element.

7. Incidentally, the verb is not used for talking about the location of a belt around the waist; the verb kle 'tie' is used for that scenario. This may be because the belt is not construed to be as closely adhering as the wrist watch is. It could also be because traditionally, waist girdles were tied onto oneself, rather than strapped.

\section{References}

Ameka, Felix K. (1999). Spatial information packaging in Ewe and Likpe: a comparative perspective. Frankfurter Afrikanistische Blätter 11, 7-34.

- (2003). Prepositions and postpositions in Ewe (Gbe): empirical and theoretical considerations. In Typologie des langues d'Afrique et universaux de la grammaire 2: Benue-kwa, Wolof, Patrick Sauzet and Anne Zibri-Hertz (eds.), 41-67. Paris: L'Harmattan.

- (2007). Grammars in contact in the Volta-Basin (West Africa): on contact induced grammatical change in Likpe. In Grammars in Contact: A Cross-Linguistic Typology, 
Alexandra Y. Aikhenvald and R. M. W. Dixon (eds.), 114-142. Oxford: Oxford University Press.

— and Essegbey, James (2006). Elements of the grammar of space in Ewe. In The Grammars of Space, Stephen C. Levinson and David P. Wilkins (eds.), 359-399. Cambridge: Cambridge University Press.

Brown, Penelope (1994). The INs and ONs of Tzeltal locative expressions: the semantics of stative descriptions of location. Linguistics 32, 743-790.

Dakubu, Mary Esther Kropp and Ford, Kevin C. (1988). The Central-Togo languages. In The Languages of Ghana, Mary Esther Kropp Dakubu (ed.), 119-154. London: Kegan Paul International/International African Institute.

Essegbey, James; Dorvlo, Kofi; and Ameka, Felix K. (2004). The southern Ghana-TogoMountain languages. Paper presented at the Endangered Languages Research in the Netherlands conference, August 2004, Free University, Amsterdam.

Goldberg, Adele (1995). Constructions: A Construction Grammar Approach to Argument Structure. Chicago: University of Chicago Press.

Heine, Bernd; Claudi, Ulrike; and Hünnemeyer, Friederike (1991). Grammaticalization: A Conceptual Framework. Chicago: University of Chicago Press.

Kita, Sotaro (2007). Linking underspecification and multi-tiered semantic representation. In Crosslinguistic Perspectives on Argument Structure: Implications for Learnability, Melissa Bowermann and Penelope Brown (eds.). Mahwah, NJ: Lawrence Earlbaum.

Levin, Beth (1993). English Verb Classes and Alternations. Chicago: Chicago University Press.

Levinson, Stephen C. (1999). H. P. Grice on location on Rossel. Berkeley Linguistic Society 25, 210-224.

-(2000). Presumptive Meanings: The Theory of Generalized Conversational Implicature. Cambridge, MA: MIT Press.

- (2003). Space in Language and Cognition: Explorations in Cognitive Diversity. Language, Culture and Cognition 5. Cambridge: Cambridge University Press.

Liu, Mei-chin (2003). Motion, direction and spatial configuration: a lexical semantic study of 'hang' verbs in Mandarin. In Motion, Direction and Location in Languages: In Honor of Zygmunt Frajzyngier, Erin Shay and Uwe Seibert (eds.), 177-187. Amsterdam: John Benjamins.

Neumann, Sabine (1999). The Locative Class in Shengologa (Kgalagadi). Frankfurt am Main: Peter Lang.

Schuh, Russell G. (1995). Avatime noun classes and concord. Studies in African Linguistics 24, 123-149.

Stewart, John M. (1989). Kwa. In The Niger-Congo Languages, John Bendor-Samuel (ed.), 217-246. Lanham, MD: University Press of America.

Talmy, Leonard (1985). Lexicalization patterns. In Language Typology and Syntactic Description, Vol. 3, T. Shopen (ed.), 57-149. Cambridge: Cambridge University Press.

- (2000). Towards a Cognitive Semantics. 2 Vols. Cambridge, MA: MIT Press.

van Staden, Miriam; Bowerman, Melissa; and Verhelst, Mariet (2006). Some properties of spatial description in Dutch. In Grammars of Space: Explorations in Cognitive Diversity, Stephen C. Levinson and David P. Wilkins (eds.), 475-511. Cambridge: Cambridge University Press.

Westermann, Dietrich and Bryan, Margaret A. (1952). Languages of West Africa: Handbook of African Languages 2. London: Oxford University Press for the International African Institute.

Williamson, Kay and Blench, Roger (2000). Niger-Congo languages. In African Languages: An Introduction, Bernd Heine and Derek Nurse (eds.), 11-42. Cambridge: Cambridge University Press. 
